\title{
Subfoveal choroidal thickness after photodynamic therapy in patients with acute idiopathic central serous chorioretinopathy
}

This article was published in the following Dove Press journal:

Therapeutics and Clinical Risk Management

9 January 2014

Number of times this article has been viewed

\author{
Yalong Dang ${ }^{1-3, \#}$ \\ Xinfeng Sun ${ }^{2, \#}$ \\ Yongsheng $\mathrm{Xu}^{3, \#}$ \\ Yalin $\mathrm{Mu}^{2}$ \\ Manli Zhao ${ }^{2}$ \\ Jing Zhao ${ }^{2}$ \\ Yu Zhu' \\ Chun Zhang ${ }^{3}$ \\ 'Department of Ophthalmology, \\ First Affiliated Hospital of \\ Zhengzhou University, Zhengzhou, \\ Henan Province, ${ }^{2}$ Department of \\ Ophthalmology, Yellow River Hospital, \\ Henan University of Science and \\ Technology, Sanmenxia, Henan \\ Province, ${ }^{3}$ Clinical Stem Cell Research \\ Center, Peking University Third \\ Hospital, Beijing, People's Republic \\ of China
}

"These authors contributed equally to this work
Correspondence: Yu Zhu First Affiliated Hospital of Zhengzhou University, Jianshe East Road, Zhengzhou, Henan Province, People's Republic of China Tel +863982289268

Fax +863982823634

Email dr.dang@aol.com

Chun Zhang

Clinical Stem Cell Research Center, Peking University Third Hospital, Beijing, People's Republic of China

Email zhang.chun@aol.com
Background: The purpose of this study was to evaluate changes in subfoveal choroidal thickness after photodynamic therapy in patients with acute idiopathic central serous chorioretinopathy (ICSCR).

Methods: This was a retrospective observational study conducted in 63 participants. The primary outcome measure was subfoveal choroidal thickness at baseline and 3 days, one week, 4 weeks, and 12 weeks after photodynamic therapy. The secondary outcome measure was indocyanine green angiography at baseline and 4 weeks and 12 weeks after photodynamic therapy.

Results: Four weeks after photodynamic therapy, 20 (64.51\%) symptomatic eyes showed hypofluorescence corresponding to the area of photodynamic therapy irradiation at the posterior pole. The mean subfoveal choroidal thickness increased significantly from $422 \pm 132 \mu \mathrm{m}$ at baseline to $478 \pm 163 \mu \mathrm{m}$ at day 3 after treatment $(P=0.022)$ and then decreased to $362 \pm 113 \mu \mathrm{m}$ at week $4(P<0.001)$ and $339 \pm 135 \mu \mathrm{m}$ at week $12(P<0.001)$.

Conclusion: The subfoveal choroid in patients with acute ICSCR is thicker than in the normal population, and in symptomatic eyes is significantly thicker than in fellow eyes. Photodynamic therapy using a one third dose of verteporfin may decrease choroidal vascular hyperpermeability and choroidal thickness in patients with acute ICSCR.

Keywords: idiopathic central serous chorioretinopathy, photodynamic therapy, subfoveal choroidal thickness, indocyanine green angiography, optical coherence tomography, enhanced depth imaging

\section{Introduction}

Idiopathic central serous chorioretinopathy (ICSCR), first described by von Graefe in 1866 , is characterized by idiopathic exudative detachment of the neurosensory retina in the posterior pole and one or more leaks from the retinal pigment epithelium. The precise pathophysiology of ICSCR is still unclear. Impairment in resorptive capacity and barrier function in retinal pigment epithelium was once considered to be an important contributing factor. However, Negi et $\mathrm{al}^{1,2}$ reported that simple dysfunction of retinal pigment epithelium could not lead to retinal detachment. Gass ${ }^{3}$ postulated that hyperpermeability of the choriocapillaris resulted in exudation of fluid into the subretinal space. Studies using indocyanine green angiography (ICGA) revealed that abnormalities of the choroidal vasculature, including hyperpermeability ${ }^{4-10}$ and venous congestion, ${ }^{10-12}$ may be the essential elements of ICSCR. ${ }^{10,11}$ Other studies ${ }^{13}$ using high-resolution ultrasonography have also shown hyperdynamic circulation within the choroid of eyes with ICSCR. ${ }^{14,15}$

Focal laser photocoagulation is a classic treatment for acute ICSCR, and can shorten the duration by about 2 months. ${ }^{16}$ However, whether it would reduce recurrence 
rates is controversial. A prospective, randomized clinical trial $^{17}$ found that the final recurrence rate in a laser photocoagulation group was unchanged. Recurrent attacks always lead to widespread decompensation of retinal pigment epithelium and permanent vision loss. Photodynamic therapy can decrease hyperpermeability in the choroid and reduce leakage from retinal pigment epithelium, hence reducing the recurrence rate. ${ }^{18-22}$ Several studies ${ }^{23-25}$ have reported that photodynamic therapy has a dose-dependent effect, and that reducing the dose of verteporfin could diminish the adverse effects in the retina and choroid. Zhao et $\mathrm{al}^{26}$ demonstrated that a $30 \%$ dose of verteporfin is safe and effective for acute ICSCR in Chinese patients.

The rapid development of imaging techniques has improved our understanding of the pathogenesis of ICSCR. Optical coherence tomography, which was invented in the late 1990s, has become an indispensible technique in evaluating and managing many ocular disorders. However, due to the signal loss occurring in the image path and the wavelength-dependent light scattering, conventional optical coherence tomography could not image the choroid clearly. Recently, Spaide et $\mathrm{al}^{27}$ described commercially available enhanced depth imaging spectral-domain optical coherence tomography (EDI-OCT) which enables quantitative measurement of choroidal thickness and topography ${ }^{27-32}$ in various diseases, such as ICSCR, ${ }^{33}$ myopia, ${ }^{34}$ age-related macular degeneration, ${ }^{28,35}$ diabetes, ${ }^{36}$ and glaucoma. ${ }^{37}$

Maruko et $\mathrm{al}^{38}$ reported that subfoveal choroidal thickness could be decreased using a half dose of photodynamic therapy in patients with ICSCR. In the current study, we performed EDI-OCT and ICGA in symptomatic eyes and fellow eyes of patients with acute ICSCR and evaluated the potential changes in subfoveal choroidal thickness after a $1 / 2$ dose of photodynamic therapy in Chinese patients.

\section{Materials and methods}

\section{Study design and patient recruitment}

This retrospective observational study was performed in consecutive patients diagnosed with unilateral acute ICSCR at the Department of Ophthalmology, Yellow River Hospital, Henan University of Science and Technology, Sanmenxia, Henan Province, People's Republic of China, from July 2011 to March 2013. The study received approval from the institutional review board of Yellow River Hospital (approval number 2011-07-03). Written informed consent was obtained from all patients, and the procedures used followed the tenets of the Declaration of Helsinki. For the comparative study, a group of healthy sex-matched and age-matched ( \pm 5 years) subjects were recruited from our students, hospital staff, and families.

\section{Diagnosis of acute ICSCR}

All participants underwent the following clinical examination: best-corrected visual acuity, slit-lamp biomicroscopy, indirect ophthalmoscopy, fluorescein angiography, and ICGA (TRC-50DX/IMAGEnet 2000; Topcon Medical Systems Inc, Tokyo, Japan). Acute ICSCR was diagnosed if patients had: subretinal fluid involving the macula associated with idiopathic leaks from the retinal pigment epithelium seen on fluorescein angiography; subretinal fluid confirmed by optical coherence tomography; and persistent serous retinal detachment for less than 6 months without widespread decompensation of the retinal pigment epithelium.

\section{Inclusion and exclusion criteria}

Inclusion criteria were: acute ICSCR; only a single eye with neurosensory retina or pigment epithelial detachment; age 20-70 years; and no spontaneous resolution after 3 months of conservative management. Exclusion criteria were: chronic ICSCR; a history of ocular disease, such as polypoidal choroidal vasculopathy, myopia, or age-related macular degeneration; a history of ocular surgery or photocoagulation; pregnancy; steroid use; and any other systemic disease.

\section{Photodynamic therapy in acute ICSCR}

The photodynamic therapy protocol was performed using a one third dose $\left(2 \mathrm{mg} / \mathrm{m}^{2}\right)$ of verteporfin (Visudine ${ }^{\circledR}$; Novartis, Basel, Switzerland) to treat patients with acute ICSCR. ${ }^{20}$ After intravenous administration of the $1 / 3$ dose of verteporfin for 10 minutes, we then used a $689 \mathrm{~nm}$ laser system (Carl Zeiss, Dublin, CA, USA) to deliver an activating laser (dose $50 \mathrm{~J} / \mathrm{cm}^{2}$ ) to the fundus of each patient. The exposure time was 83 seconds. The laser spot size was the diameter of the hyperpermeability region of ICGA plus $500 \mu \mathrm{m}$.

\section{Examination of subfoveal choroidal thickness}

Subfoveal choroidal thickness was evaluated in the patients with acute ICSCR at baseline and 3 days, one week, 4 weeks, and 12 weeks after photodynamic therapy. The choroid was observed by EDI-OCT (Spectralis HRA + OCT, Heidelberg Engineering, Heidelberg, Germany). The device was positioned close to the eye to obtain inverted images of the fundus, but the images were reinverted for display. Eye tracking was used during measurement. Seven sections, each containing 25 averaged raw scans, were obtained within a 5-30 degree 
rectangle centered on the fovea. Choroidal thickness (defined as the zonal area between the inner scleral surface and the outer retinal pigment epithelium surface) was measured subfoveally on the transfoveolar scan using the manufacturer's software (Heidelberg Eye Explorer version 1.6.1.0). Although the thickest section of the choroid might not be at the subfoveal region, in this study we measured the subfoveal choroidal thickness as an indicator to avoid selection bias. All measurements were performed independently by two experienced examiners. If the measurements differed by more than $15 \%$, the examiners performed the measurement together twice.

\section{Statistical analyses}

All data was analyzed by PASW statistics version 18.0 (SPSS Inc, Chicago, IL, USA). The independent $t$-test, paired $t$-test, or least significant difference $t$-test was used to evaluate subfoveal choroidal thickness. Fisher's Exact tests were used to compare the difference in other clinical data. Results were considered to be statistically significant at $P$-values of 0.05 .

\section{Results}

\section{Baseline demographic characteristics}

A total of 63 patients were finally enrolled, ie, 31 patients in the photodynamic therapy group and 32 patients in the control group. There was no statistically significant difference between the two groups with regard to mean age and sex ( $P=0.68$ and $P=0.78$, respectively). The mean spherical equivalent refractive error in the photodynamic therapy group was $-1.69 \pm 2.24$ diopters compared with $-2.54 \pm 1.96$ diopters in the control group; the difference was statistically significant $(P=0.02)$. The mean interval between onset of symptoms and treatment in the photodynamic therapy group was $45.74 \pm 22.85$ weeks (Table 1 ).

Table I Baseline demographic characteristics

\begin{tabular}{|c|c|c|c|}
\hline & $\begin{array}{l}\text { PDT group } \\
(n=3 I)\end{array}$ & $\begin{array}{l}\text { Control group } \\
(n=32)\end{array}$ & $P$-value \\
\hline \multicolumn{4}{|l|}{ Age (years) } \\
\hline Mean \pm SD & $45.63 \pm 6.24$ & $47.24 \pm 5.93$ & 0.68 \\
\hline Range & $28-67$ & $22-69$ & \\
\hline \multicolumn{4}{|l|}{ Sex } \\
\hline Male to female & $26: 5$ & $27: 5$ & 0.78 \\
\hline \multicolumn{4}{|c|}{ Spherical equivalent refractive error (diopters) } \\
\hline Mean \pm SD & $-1.69 \pm 2.24$ & $-2.54 \pm 1.96$ & 0.02 \\
\hline Range & -3.50 to 2.75 & -3.75 to 2.75 & \\
\hline \multicolumn{4}{|c|}{ Interval between onset of symptoms and treatment (weeks) } \\
\hline Mean \pm SD & $45.74 \pm 22.85$ & - & - \\
\hline Range & $28-62$ & - & - \\
\hline
\end{tabular}

Abbreviations: PDT, photodynamic therapy; SD, standard deviation.

\section{Characteristics of ICGA}

Of the 64 eyes from the 32 patients in the control group, ten $(15.63 \%)$ had hyperfluorescence defined as choroidal vascular hyperpermeability in the middle phase of ICGA and 54 eyes (84.37\%) did not have hyperfluorescence.

In the photodynamic therapy group, before treatment, $30(96.78 \%)$ symptomatic eyes and $23(74.19 \%)$ fellow eyes from 31 patients showed a mottling hyperfluorescence in the middle phase of ICGA. Four weeks after treatment, we found that $20(64.51 \%)$ symptomatic eyes showed hypofluorescence corresponding to the area of photodynamic therapy irradiation at the posterior pole. The rate of choroidal vascular hyperpermeability in the fellow eye remained unchanged. This phenomenon persisted throughout the study.

\section{Changes in subfoveal choroidal thickness}

The mean subfoveal choroid thickness changes at baseline and follow-up are summarized in Tables 2, 3 and Figure 1. At baseline, the mean subfoveal choroid thickness in symptomatic eyes was significantly greater than in fellow eyes (422 $\pm 132 \mu \mathrm{m}$ and $367 \pm 114 \mu \mathrm{m}$, respectively, $P=0.036$ ). Mean subfoveal choroid thickness in the fellow eyes was significantly greater than in the control group $(367 \pm 114 \mu \mathrm{m}$ and $274 \pm 53 \mu \mathrm{m}$, respectively, $P<0.001$ ).

Based on the ICGA, the mean subfoveal choroid thickness of fellow eyes with hyperfluorescence was significantly greater than those without hyperpermeability $(446 \pm 105 \mu \mathrm{m}$ versus $279 \pm 115 \mu \mathrm{m}, P<0.001)$. When comparing the difference between subfoveal choroidal thickness in the fellow eyes without hyperfluorescence and that in the control group, we found a negative result $(279 \pm 115 \mu \mathrm{m}$ versus $274 \pm 53 \mu \mathrm{m}$, $P=0.520)$.

After photodynamic therapy, the mean subfoveal choroidal thickness increased significantly from $422 \pm 132 \mu \mathrm{m}$ at baseline to $478 \pm 163 \mu \mathrm{m}$ at day $3(P=0.022)$ and then decreased to $362 \pm 113 \mu \mathrm{m}$ at week $4(P<0.001$ versus baseline $)$ and to $339 \pm 135 \mu \mathrm{m}$ at week $12(P<0.001$ versus baseline, Figure 1). During follow-up, an interesting case occurred in the photodynamic therapy group (Figure 2).

\section{Absorption of subretinal fluid}

At successive follow-ups, the subretinal fluid in 19 patients decreased significantly at 4 weeks after photodynamic therapy, but not at day 3 and week 1 . After 12 weeks of follow-up, the subretinal fluid in 25 patients was already fully absorbed. 
Table 2 Subfoveal choroidal thickness at baseline

\begin{tabular}{|c|c|c|c|c|}
\hline & \multicolumn{3}{|l|}{ PDT group } & \multirow{2}{*}{$\begin{array}{l}\text { Control group } \\
(n=64)\end{array}$} \\
\hline & $\begin{array}{l}\text { Symptomatic eyes } \\
(n=3 I)\end{array}$ & $\begin{array}{l}\text { Fellow eyes with } \\
\text { hyperfluorescence } \\
\text { in ICGA }(n=23)\end{array}$ & $\begin{array}{l}\text { Fellow eyes with } \\
\text { hyperfluorescence } \\
\text { in ICGA }(n=8)\end{array}$ & \\
\hline Mean \pm SD & $422 \pm 132$ & $446 \pm 105$ & $279 \pm 115$ & $274 \pm 53$ \\
\hline Range & $136-642$ & $331-642$ & $136-372$ & $97-335$ \\
\hline
\end{tabular}

Notes: Among-group comparison using Student's independent or paired $t$-tests. $P$-values $<0.05$ are considered to be statistically significant. Abbreviations: ICGA, indocyanine green angiography; PDT, photodynamic therapy; SD, standard deviation.

\section{Safety}

During follow-up, no adverse systemic or ocular events occurred.

\section{Discussion}

In the current study, we used EDI-OCT to evaluate changes in subfoveal choroid thickness after photodynamic therapy in patients with acute ICSCR. Our findings support the view that photodynamic therapy can decrease choroidal vascular hyperpermeability and choroidal thickness. Our findings also showed that the subfoveal choroid in patients with acute ICSCR was thicker than in healthy subjects, with the subfoveal choroid in symptomatic eyes being significantly thicker than in the fellow eyes. To our knowledge, this is the first study using EDI-OCT to quantitatively assess changes in subfoveal choroidal thickness after a one third dose of photodynamic therapy in a relatively large sample of patients with acute ICSCR.

Subfoveal choroidal thickness in healthy subjects has been reported to be between $261 \mu \mathrm{m}$ and $354 \mu \mathrm{m} .{ }^{29,30,39-42}$ Our study showed that mean subfoveal choroidal thickness in the control group was $274 \mu \mathrm{m}$. The variation in results

Table 3 Subfoveal choroidal thickness during follow-up

\begin{tabular}{|c|c|c|}
\hline & $\begin{array}{l}\text { PDT group } \\
\text { (symptomatic } \\
\text { eyes, } n=31 \text { ) }\end{array}$ & $\begin{array}{l}\text { PDT group } \\
\text { (fellow eyes, } \\
n=3 I \text { ) }\end{array}$ \\
\hline \multicolumn{3}{|c|}{ Choroidal thickness at baseline $(\mu \mathrm{m})$} \\
\hline Mean \pm SD & $422 \pm 132$ & $367 \pm 114$ \\
\hline Range & $136-642$ & $113-573$ \\
\hline \multicolumn{3}{|c|}{ Three days follow-up $(\mu \mathrm{m})$} \\
\hline Mean \pm SD & $478 \pm 163$ & $37 I \pm 123$ \\
\hline Range & $157-668$ & $|2|-569$ \\
\hline \multicolumn{3}{|c|}{ Four weeks follow-up $(\mu \mathrm{m})$} \\
\hline Mean \pm SD & $362 \pm 113$ & $368 \pm 134$ \\
\hline Range & II2-574 & $|08-58|$ \\
\hline \multicolumn{3}{|c|}{ Twelve weeks follow-up $(\mu \mathrm{m})$} \\
\hline Mean \pm SD & $339 \pm 135$ & $368 \pm 121$ \\
\hline Range & $108-578$ & $115-575$ \\
\hline
\end{tabular}

Notes: Among-group comparison using Student independent or paired $t$-tests. $P$-values $<0.05$ were considered to be statistically significant.

Abbreviations: PDT, photodynamic therapy; SD, standard deviation. from the different studies may be attributable to variations in patient age, sex, axial length, and refractive condition, as well as the optical coherence tomography device used. Patient age $^{28,30,40,43}$ has been recognized as the most influential factor in choroidal thickness. An EDI-OCT-based study undertaken by Margolis and Spaide ${ }^{30}$ reported mean decreases in choroidal thickness of $15.6 \mu \mathrm{m}$ per year in normal eyes. Ikuno et $\mathrm{al}^{40}$ confirmed this finding. However, this theory might not suit for ICSCR patients. Imamura et $\mathrm{l}^{33}$ reported that choroidal thickness did not correlate with age in ICSCR patients $(r=0.15, P=0.43)$. Axial length is another important influencing factor. Li et $\mathrm{al}^{42}$ reported that subfoveal choroidal thickness decreased by $58.2 \mu \mathrm{m}$ per mm increase in axial length adjusted for age and sex. Esmaeelpour et a ${ }^{44}$ agreed with this view, and found that axial length was the most important determinant of choroidal thickness. Further, sex has been reported as another influential factor in choroidal thinning. In a multiple regression model, ${ }^{42}$ after adjustment for age and axial length, subfoveal choroidal thickness was on average $62 \mu \mathrm{m}$ thicker in men than in women (95\% confidence interval 21-104; $P=0.0039)$. In contrast, Park and $\mathrm{Oh}^{45}$ analyzed the association between sex and choroidal thickness, and found that the mean subfoveal thickness in males was $9 \mu \mathrm{m}$ thicker than in females, but the difference was not significantly different $(P>0.05)$. Moreover, an association between refractive condition and subfoveal choroidal thickness has also been reported. Ho et al ${ }^{46}$ suggested that subfoveal choroidal thickness decreased by $6.205 \mu \mathrm{m}$ for each diopter in patients with myopia. However, ICSCR patients are often hyperopic. In the current study, the mean spherical equivalent refractive error in the photodynamic therapy group was $-1.69 \pm 2.24$ diopters compared with $-2.54 \pm 1.96$ diopters in the control group; this difference reached statistical significance $(P=0.02)$. This might be one reason why the subfoveal choroid in patients with ICSCR is thicker than in the normal population.

Most acute ICSCR is actually bilateral, even if subretinal fluid is active in one eye. Choroidal vascular hyperpermeability might have a crucial role in ICSCR. In an ICGA study, 


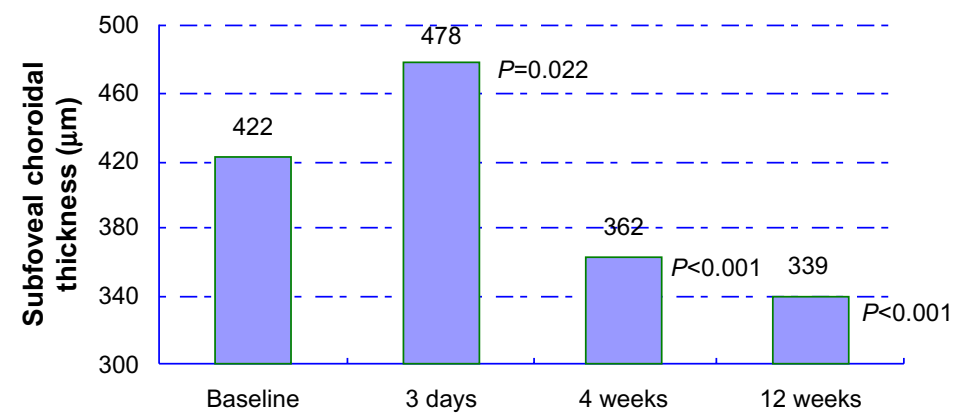

Figure I The changes of subfoveal choroidal thickness after photodynamic therapy.

Iida et $\mathrm{al}^{10}$ found that the incidence of choroidal vascular hyperpermeability was $62 \%$ in fellow eyes compared with $95 \%$ in symptomatic eyes. In the current study, $96.78 \%$ of symptomatic eyes and $74.19 \%$ of fellow eyes showed hyperfluorescence in the middle phase of ICGA in the photodynamic therapy group. This is similar to the findings of a study reported by Maruko et al. ${ }^{47}$ Choroidal vascular hyperpermeability is always accompanied by choroid thickening in ICSCR patients. Imamura et $\mathrm{al}^{33}$ reported that the choroid in patients with ICSCR was thicker bilaterally (including for symptomatic eyes and fellow eyes) than in normal eyes. In our study, the subfoveal choroid in symptomatic eyes was significantly thicker than in fellow eyes $(P=0.036)$, and the subfoveal choroid in fellow eyes was significantly thicker than in age-matched and sex-matched control eyes $(P<0.001)$. The subfoveal choroid thickness of the fellow eyes with hyperfluorescence in ICGA was significantly higher than that in those without hyperpermeability $(P<0.001)$. When we compared the difference between subfoveal choroidal thickness in the fellow eyes without hyperfluorescence and the control eyes, we found a negative result $(P=0.520)$. These findings indicate that choroidal vascular hyperpermeability plays an important role in pathophysiology of ICSCR.

Photodynamic therapy with verteporfin, which has an occlusive effect in the choriocapillary layers, could decrease choroidal vascular hyperpermeability and subsequently choroidal thickness. ${ }^{18,21}$ Schlotzer-Schrehardt et al ${ }^{24}$ and SchmidtErfurth et $\mathrm{al}^{25}$ reported that photodynamic therapy has a dose-dependent profile. Increasing the dose of verteporfin or laser irradiation would increase the risk of vascular damage or cytotoxicity to the retina and choroid. It is important to balance the maximum therapeutic effect and the minimum complications. Half-dose photodynamic therapy ${ }^{38}$ has been used widely to treat ICSCR, but might not be suitable for
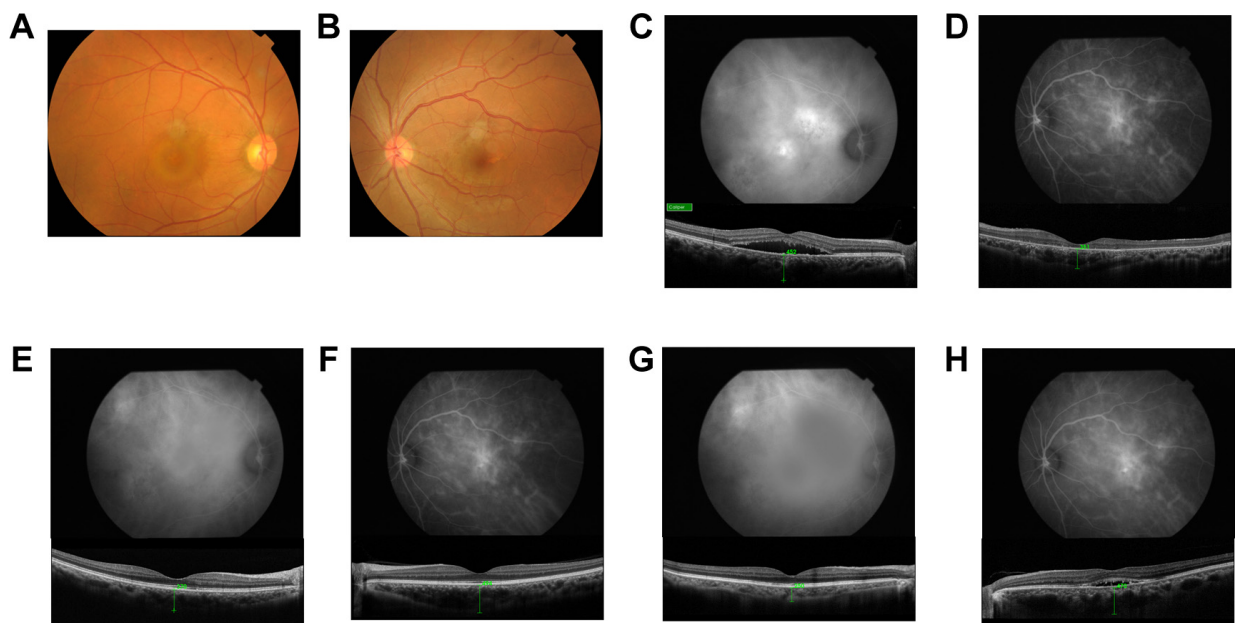

Figure 2 Case I, a 36-year-old man with blurred vision in his right eye. (A) A fundus photograph of the right eye showing a serous retinal detachment at the fovea. (B) Fundus photograph of the left eye is normal. (C and D) ICGA showed bilateral choroidal vascular hyperpermeability in middle-phase. The subfoveal choroidal thickness at the baseline was $452 \mu \mathrm{m}$ in the right eye and $35 \mathrm{I} \mu \mathrm{m}$ in the left eye. (E and F) After PDT, the subfoveal choroidal thickness in his right eye decreased to $370 \mu \mathrm{m}$ at week 4. However, the subfoveal choroidal thickness in the left eye increased to $494 \mu \mathrm{m}$, with ICGA indicating aggravation of his choroidal vascular hyperpermeability. (G and $\mathbf{H}$ ) At week II, in his left eye, ICGA showed aggravation of choroidal vascular hyperpermeability in middle-phase, with a subfoveal choroidal thickness of $470 \mu \mathrm{m}$. Abbreviations: ICGA, indocyanine green angiography; PDT, photodynamic therapy. 
Chinese patients. Zhao et $\mathrm{al}^{26}$ used photodynamic therapy with various doses of verteporfin $(70 \%, 60 \%, 50 \%, 40 \%$, $30 \%, 20 \%$, and $10 \%$ of the full dose) to manage ICSCR patients, and their results showed that $30 \%$ of the full dose of verteporfin was the lowest effective dose. In our study, following the recommendation of Zhao et al, we chose the $30 \%$ dose of verteporfin to manage our ICSCR patients. To our surprise, the mean choroidal thickness increased significantly from $422 \pm 132 \mu \mathrm{m}$ at baseline to $478 \pm 163 \mu \mathrm{m}$ at day 3. This transient increase in choroidal thickness may be a sign of increased exudation in the choroid. Eventually, after impairment of the choriocapillaris and vascular remodeling in the underlying choroid, the choroidal thickness decreased to $362 \pm 113 \mu \mathrm{m}$ at week 4 and to $339 \pm 135 \mu \mathrm{m}$ at week 12 . Accompanying the changes in choroidal thickness, at week 4 , we found that $64.51 \%$ of symptomatic eyes showed hypofluorescence corresponding to the area of photodynamic therapy irradiation at the posterior pole. Maruko et $\mathrm{al}^{38}$ reported similar findings, ie, mean choroidal thickness increased from $389 \pm 106 \mu \mathrm{m}$ at baseline to $462 \pm 124 \mu \mathrm{m}(P=0.008)$ on day 2 after treatment, then reduced to $360 \pm 100 \mu \mathrm{m}$ at week 1 and to $330 \pm 103 \mu \mathrm{m}$ at week 4 , with ICGA also showing decreased hyperpermeability. Maruko et $\mathrm{al}^{38}$ used photodynamic therapy with a half dose $\left(3 \mathrm{mg} / \mathrm{m}^{2}\right)$ of verteporfin, which was higher than that $\left(2 \mathrm{mg} / \mathrm{m}^{2}\right)$ used in our study, but with similar efficacy. Recently, a prospective, nonrandomized, consecutive, open-label case series conducted by Uetani et $\mathrm{al}^{48}$ reported an opposite outcome. In that study, Uetani et al compared the effects of a half-dose of verteporfin with those of a one-third dose of verteporfin for ICSCR. In the half-dose photodynamic therapy group, choroidal thickness reduced significantly from baseline. However, in the $1 / 3$ dose photodynamic therapy group, choroidal thickness decreased in two eyes in which subretinal fluid disappeared, but did not change in the other eyes. However, only six patients were assigned to the photodynamic therapy group in that study, so the sample size was relatively small which might have led to bias.

Our retrospective study has some limitations. Acute ICSCR is well known to recur in some cases, so 3 months of follow-up seems to be short. A long-term study to evaluate the changes in subfoveal choroidal thickness and recurrence rate after photodynamic therapy is necessary. Additionally, the current EDI-OCT does not have automatic choroid segmentation software. Manual operation might lead to inaccuracy in some cases, so automatic choroid segmentation software is needed in future research. Moreover, the relationship between severity of hyperpermeability in ICGA and choroidal thickening should be investigated.
In conclusion, our findings revealed that: the subfoveal choroid in patients with acute ICSCR was thicker than in the normal population, with symptomatic eyes being significantly thicker than in fellow eyes; compared with half-dose or fulldose photodynamic therapy, a one-third dose of verteporfin could decrease choroidal vascular hyperpermeability and choroidal thickness in patients with acute ICSCR.

\section{Disclosure}

The authors report no conflicts of interests in this work.

\section{References}

1. Negi A, Marmor MF. Experimental serous retinal detachment and focal pigment epithelial damage. Arch Ophthalmol. 1984;102(3):445-449.

2. Negi A, Marmor MF. The resorption of subretinal fluid after diffuse damage to the retinal pigment epithelium. Invest Ophthalmol Vis Sci. 1983;24(11):1475-1479.

3. Gass JD. Pathogenesis of disciform detachment of the neuroepithelium. Am J Ophthalmol. 1967;63(Suppl 3):1-139.

4. Spaide RF, Goldbaum M, Wong DW, Tang KC, Iida T. Serous detachment of the retina. Retina. 2003;23(6):820-846.

5. Hayashi K, Hasegawa Y, Tokoro T. Indocyanine green angiography of central serous chorioretinopathy. Int Ophthalmol. 1986;9(1):37-41.

6. Guyer DR, Yannuzzi LA, Slakter JS, Sorenson JA, Ho A, Orlock D. Digital indocyanine green videoangiography of central serous chorioretinopathy. Arch Ophthalmol. 1994;112(8):1057-1062.

7. Spaide RF, Hall L, Haas A, et al. Indocyanine green videoangiography of older patients with central serous chorioretinopathy. Retina. 1996;16(3): 203-213.

8. Spaide RF, Campeas L, Haas A, et al. Central serous chorioretinopathy in younger and older adults. Ophthalmology. 1996;103(12):2070-2079.

9. Shiraki K, Moriwaki M, Matsumoto M, Yanagihara N, Yasunari T, Miki T. Long-term follow-up of severe central serous chorioretinopathy using indocyanine green angiography. Int Ophthalmol. 1997-1998;21(5): 245-253.

10. Iida T, Kishi S, Hagimura N, Shimizu K. Persistent and bilateral choroidal vascular abnormalities in central serous chorioretinopathy. Retina. 1999;19(6):508-512.

11. Prunte C, Flammer J. Choroidal capillary and venous congestion in central serous chorioretinopathy. Am J Ophthalmol. 1996;121(1):26-34.

12. Giovannini A, Scassellati-Sforzolini B, D'Altobrando E, Mariotti C, Rutili T, Tittarelli R. Choroidal findings in the course of idiopathic serous pigment epithelium detachment detected by indocyanine green videoangiography. Retina. 1997;17(4):286-293.

13. Doro D, Visentin S, Maimone PE, Pilotto E. High-resolution ultrasonography in central serous chorioretinopathy. Am J Ophthalmol. 2005;139(3):550-552.

14. Tittl M, Polska E, Kircher K, et al. Topical fundus pulsation measurement in patients with active central serous chorioretinopathy. Arch Ophthalmol. 2003;121(7):975-978.

15. Tittl M, Maar N, Polska E, Weigert G, Stur M, Schmetterer L. Choroidal hemodynamic changes during isometric exercise in patients with inactive central serous chorioretinopathy. Invest Ophthalmol Vis Sci. 2005;46(12):4717-4721.

16. Robertson DM, Ilstrup D. Direct, indirect, and sham laser photocoagulation in the management of central serous chorioretinopathy. Am J Ophthalmol. 1983;95(4):457-466.

17. Ficker L, Vafidis G, While A, Leaver P. Long-term follow-up of a prospective trial of argon laser photocoagulation in the treatment of central serous retinopathy. Br J Ophthalmol. 1988;72(11):829-834.

18. Yannuzzi LA, Slakter JS, Gross NE, et al. Indocyanine green angiography guided photodynamic therapy for treatment of chronic central serous chorioretinopathy: a pilot study. Retina. 2003;23(3):288-298. 
19. Cardillo Piccolino F, Eandi CM, Ventre L, Rigault de la Longrais RC, Grignolo FM. Photodynamic therapy for chronic central serous chorioretinopathy. Retina. 2003;23(6):752-763.

20. Chan WM, Lai TY, Lai RY, Tang EW, Liu DT, Lam DS. Safety enhanced photodynamic therapy for chronic central serous chorioretinopathy: one-year results of a prospective study. Retina. 2008;28(1): 85-93.

21. Chan WM, Lai TY, Lai RY, Liu DT, Lam DS. Half-dose verteporfin photodynamic therapy for acute central serous chorioretinopathy: one-year results of a randomized controlled trial. Ophthalmology. 2008;115(10): 1756-1765.

22. Shin JY, Woo SJ, Yu HG, Park KH. Comparison of efficacy and safety between half-fluence and full-fluence photodynamic therapy for chronic central serous chorioretinopathy. Retina. 2011;31(1):119-126.

23. Schmidt-Erfurth U, Laqua H, Schlötzer-Schrehard U, Viestenz A, Naumann GO. Histopathological changes following photodynamic therapy in human eyes. Arch Ophthalmol. 2002;120(6):835-844.

24. Schlotzer-Schrehardt U, Viestenz A, Naumann GO, Laqua H, Michels S, Schmidt-Erfurth U. Dose-related structural effects of photodynamic therapy on choroidal and retinal structures of human eyes. Graefes Arch Clin Exp Ophthalmol. 2002;240(9):748-757.

25. Schmidt-Erfurth U, Michels S, Barbazetto I, Laqua H. Photodynamic effects on choroidal neovascularization and physiological choroid. Invest Ophthalmol Vis Sci. 2002;43(3):830-841.

26. Zhao MW, Zhou P, Xiao HX, et al. Photodynamic therapy for acute central serous chorioretinopathy: the safe effective lowest dose of verteporfin. Retina. 2009;29(8):1155-1161.

27. Spaide RF, Koizumi H, Pozzoni MC. Enhanced depth imaging spectraldomain optical coherence tomography. Am J Ophthalmol. 2008;146(4): 496-500.

28. Spaide RF. Age-related choroidal atrophy. Am J Ophthalmol. 2009;147(5):801-810.

29. Branchini L, Regatieri CV, Flores-Moreno I, Baumann B, Fujimoto JG, Duker JS. Reproducibility of choroidal thickness measurements across three spectral domain optical coherence tomography systems. Ophthalmology. 2012;119(1):119-123.

30. Margolis R, Spaide RF. A pilot study of enhanced depth imaging optical coherence Am J Ophthalmol. 2009;147(5):811-815

31. Barteselli G, Chhablani J, El-Emam S, et al. Choroidal volume variations with age, axial length, and sex in healthy subjects: a three-dimensional analysis. Ophthalmology. 2012;119(12):2572-2578.

32. Chhablani J, Barteselli G, Wang H, et al. Repeatability and reproducibility of manual choroidal volume measurements using enhanced depth imaging optical coherence tomography. Invest Ophthalmol Vis Sci. 2012;53(4):2274-2280.

33. Imamura Y, Fujiwara T, Margolis R, Spaide RF. Enhanced depth imaging optical coherence tomography of the choroid in central serous chorioretinopathy. Retina. 2009;29(10):1469-1473.
34. Fujiwara T, Imamura Y, Margolis R, Slakter JS, Spaide RF. Enhanced depth imaging optical coherence tomography of the choroid in highly myopic eyes. Am J Ophthalmol. 2009;148(3):445-450.

35. Koizumi H, Yamagishi T, Yamazaki T, Kawasaki R, Kinoshita S. Subfoveal choroidal thickness in typical age-related macular degeneration and polypoidal choroidal vasculopathy. Graefes Arch Clin Exp Ophthalmol. 2011;249(8):1123-1128.

36. Esmaeelpour M, Povazay B, Hermann B, et al. Mapping choroidal and retinal thickness variation in type 2 diabetes using three-dimensional 1060-nm optical coherence tomography. Invest Ophthalmol Vis Sci. 2011;52(8):5311-5316.

37. Maul EA, Friedman DS, Chang DS, et al. Choroidal thickness measured by spectral domain optical coherence tomography: factors affecting thickness in glaucoma patients. Ophthalmology. 2011;118(8):1571-1579.

38. Maruko I, Iida T, Sugano Y, Ojima A, Ogasawara M, Spaide RF. Subfoveal choroidal thickness after treatment of central serous chorioretinopathy. Ophthalmology. 2010;117(9):1792-1799.

39. Ding X, Li J, Zeng J, et al. Choroidal thickness in healthy Chinese subjects. Invest Ophthalmol Vis Sci. 2011;52(13):9555-9560.

40. Ikuno Y, Kawaguchi K, Nouchi T, Yasuno Y. Choroidal thickness in healthy Japanese subjects. Invest Ophthalmol Vis Sci. 2010;51(4): 2173-2176.

41. Manjunath V, Taha M, Fujimoto JG, Duker JS. Choroidal thickness in normal eyes measured using Cirrus HD optical coherence tomography. Am J Ophthalmol. 2010;150(3):325-329.

42. Li XQ, Larsen M, Munch IC. Subfoveal choroidal thickness in relation to sex and axial length in 93 Danish university students. Invest Ophthalmol Vis Sci. 2011;52(11):8438-8441.

43. Ramrattan RS, van der Schaft TL, Mooy CM, de Bruijn WC, Mulder PG, de Jong PT. Morphometric analysis of Bruch's membrane, the choriocapillaris, and the choroid in aging. Invest Ophthalmol Vis Sci. 1994;35(6):2857-2864.

44. Esmaeelpour M, Povazay B, Hermann B, et al. Three-dimensional 1060$\mathrm{nm}$ OCT: choroidal thickness maps in normal subjects and improved posterior segment visualization in cataract patients. Invest Ophthalmol Vis Sci. 2010;51(10):5260-5266.

45. Park KA, Oh SY. Choroidal thickness in healthy children. Retina. 2013;33(9):1971-1976.

46. Ho M, Liu DT, Chan VC, Lam DS. Choroidal thickness measurement in myopic eyes by enhanced depth optical coherence tomography. Ophthalmology. 2013;120(9):1909-1914.

47. Maruko I, Iida T, Sugano Y, Ojima A, Sekiryu T. Subfoveal choroidal thickness in fellow eyes of patients with central serous chorioretinopathy Retina. 2011;31(8):1603-1608.

48. Uetani R, Ito Y, Oiwa K, Ishikawa K, Terasaki H. Half-dose vs one-thirddose photodynamic therapy for chronic central serous chorioretinopathy Eye (Lond). 2012;26(5):640-649.
Therapeutics and Clinical Risk Management

\section{Publish your work in this journal}

Therapeutics and Clinical Risk Management is an international, peerreviewed journal of clinical therapeutics and risk management, focusing on concise rapid reporting of clinical studies in all therapeutic areas, outcomes, safety, and programs for the effective, safe, and sustained use of medicines. This journal is indexed on PubMed Central, CAS,

\section{Dovepress}

EMBase, Scopus and the Elsevier Bibliographic databases. The manuscript management system is completely online and includes a very quick and fair peer-review system, which is all easy to use. Visit http://www.dovepress.com/testimonials.php to read real quotes from published authors. 